\title{
Ischemic mitral regurgitation: Individualized treatment prevails
}

\author{
Ehud Raanani, MD
}

See related article on pages $1595-603$.

For years now, the surgical community has been living under the assumption that mitral valve annuloplasty (MVA) is always superior to mitral valve replacement (MVR) in the treatment of ischemic mitral regurgitation (IMR). It has become apparent, however, that this was no more than conjecture that was based on weak evidence from several retrospective, nonrandomized studies that reported lower early and late mortalities among patients who had undergone MVA rather than MVR. ${ }^{1}$ In those nonrandomized studies, patients who had undergone MVR were older with more comorbidities, factors that are difficult to adjust or control.

Nevertheless, currently, the most common procedure for the treatment of IMR remains the simple "restrictive annuloplasty" method with downsized, closed, D-shaped rigid or semirigid rings. The concept behind this procedure is to overcome the tethering effect by aggressively reducing the annular anteroposterior diameter, thereby achieving an 8-mm leaflet coaptation length.

For some time, surgeons were concerned only with the fact that this procedure resulted in a significant rate of mitral regurgitation recurrence, which reached proportions of between $25 \%$ and $40 \%$ at 3 to 5 years of follow-up. This high recurrence rate was attributed mainly to the fact that IMR is not a leaflet disease but a myocardial pathology that in many cases is progressive, with negative remodeling of the failed heart, which continues to dilate, thereby increasing the apical tethering effect of the mitral valve leaflets.

To reduce the recurrence of mitral regurgitation, it was suggested that a variety of adjunct ventricular or leaflet surgical procedures be performed in combination with the annuloplasty. These included papillary muscle maneuvers, anterior or posterior leaflet extension, secondary chordal cutting, and more. None of these procedures gained widespread popularity in a real-life setting, however, because of surgical complexity, mixed results, or lack of reproducibility.

From the Department of Cardiac Surgery, Sheba Medical Center, Ramat-Gan, Israel. Disclosures: Author has nothing to disclose with regard to commercial support.

Received for publication March 20, 2015; accepted for publication March 20, 2015; available ahead of print April 16, 2015.

Address for reprints: Ehud Raanani, MD, Department of Cardiac Surgery, Sheba Medical Center, Ramat-Gan 52561, Israel (E-mail: Ehud.raanani@sheba.health. gov.il).

J Thorac Cardiovasc Surg 2015;149:1604-5

0022-5223/\$36.00

Copyright (c) 2015 by The American Association for Thoracic Surgery

http://dx.doi.org/10.1016/j.jtcvs.2015.03.038

A further effort to reduce mitral regurgitation recurrence and improve durability is the development of new types of annuloplasty rings. Several types of 3-dimensional shaped or adjustable annuloplasty rings have been developed specifically for the treatment of IMR. Some show promising early results, although longterm outcomes are as yet unavailable.

The study in this issue of the Journal by Fino and colleagues, ${ }^{2}$ a continuation of a previous study by the same authors, ${ }^{3}$ elaborates on the fact that recurrent mitral regurgitation is not the only caveat of restrictive annuloplasty. Fino and colleagues maintain that in this procedure some patients pay the "price" of trying to achieve "optimal" postoperative echocardiographic results with a long coaptation line and no mitral regurgitation.

In this issue, Fino and colleagues compared late clinical (6-minute walk testing) and hemodynamic profiles (exercise echocardiography) between patients who underwent restrictive MVA or MVR for IMR. They succeeded in demonstrating that as a whole the group that underwent MVA had significantly worse outcomes. This finding is in accord with other recent studies, which showed that MVA may not always be superior to MVR in terms of both hemodynamics and late clinical outcomes. ${ }^{4,5}$

Because of the effect of the small rigid ring and the immobile posterior leaflet in many patients, the remaining effective orifice area of the mitral valve becomes too small and in time may become even smaller as a result of late increased stiffness of the leaflets. Consequently, this problem translates into poor mitral valve diastolic hemodynamic properties and poor clinical functional status.

First year follow-up results of the prospective, randomized multicenter study recently published in the New England Journal of Medicine that compared MVA with "chordal sparing MVR" in patients with IMR, showed neither clinical nor echocardiographic advantages of MVA. ${ }^{6}$ Significantly, this study also included all types of patients with IMR, including those with severe leaflet tethering, thus resulting in a $30 \%$ recurrence of mitral regurgitation. These recent studies are particularly important because they raise the serious question of whether MVA is indeed the optimal treatment for all types of patients with IMR.

The answer to this question is probably no. For now, there is no single procedure that is suitable for all. This is because not all patients with IMR are the same and thus cannot be placed in the same basket. There are many anatomic and 
clinical differences among patients with IMR, such as severity and asymmetry of tethering, preoperative left ventricular end-diastolic diameter, left ventricular dyssynchrony, interpapillary distance, and time from infarct, all of which will affect the late success rate of MVA in terms of the risk of mitral regurgitation recurrence or future valve stenosis.

Now more than ever we are close to the point where there is sufficient accumulated data to provide comprehensive preoperative imaging, stratify patients, and tailor their needs to individual surgical treatment. Some patients will benefit most from simple restrictive MVA, some from nonrestrictive MVA combined with more complex maneuvers, and some from dedicated preshaped rings, whereas the remaining patients will benefit most from simple MVR with complete chordal sparing.

\section{References}

1. Gillinov AM, Wierup PN, Blackstone EH, Bishay ES, Cosgrove DM, White J, et al. Is repair preferable to replacement for ischemic mitral regurgitation? J Thorac Cardiovasc Surg. 2001;122:1125-41

2. Fino C, Iacovoni A, Ferrero P, Merlo M, Bellavia D, D’Elia E, et al. Determinants of functional capacity after mitral valve annuloplasty or replacement for ischemic mitral regurgitation. J Thorac Cardiovasc Surg. 2015;149:1595-603.

3. Fino C, Iacovoni A, Ferrero P, Senni M, Merlo M, Cugola D, et al. Restrictive mitral valve annuloplasty versus mitral valve replacement for functional ischemic mitral regurgitation: an exercise echocardiographic study. J Thorac Cardiovasc Surg. 2014; 148:447-53.e2.

4. Lorusso R, Gelsomino S, Vizzardi E, D’Aloia A, De Cicco G, Lucà F, et al. Mitra valve repair or replacement for ischemic mitral regurgitation? The Italian Study on the Treatment of Ischemic Mitral Regurgitation (ISTIMIR). J Thorac Cardiovasc Surg. 2013;145:128-39; discussion 137-8.

5. Dayan V, Soca G, Cura L, Mestres CA. Similar survival after mitral valve replacement or repair for ischemic mitral regurgitation: a meta-analysis. Ann Thorac Surg. 2014;97:758-65.

6. Acker MA, Parides MK, Perrault LP, Moskowitz AJ, Gelijns AC, Voisine P, et al CTSN. Mitral-valve repair versus replacement for severe ischemic mitral regurgitation. N Engl J Med. 2014;370:23-32. 